\title{
THE EFFECT OF N-METHYLATION ON CERTAIN IMINAZOLINES
}

\author{
BY \\ C. W. GOWDEY \\ From the Department of Pharmacology, Oxford
}

(Received August 20, 1948)

In a previous paper (Gowdey, 1948) it has been shown that methylation of a nitrogen atom in the iminazoline ring of 2-benzyliminazoline (BI) produces important changes in its pharmacological activity. Thus the $\mathrm{N}$-methyl derivative, instead of causing a fall of blood pressure through peripheral vasodilatation, caused a rise of blood pressure, but had no direct effect on vessels, and the pressor effect was shown to be due to a nicotine-like liberation of adrenaline from the adrenals. On the other

TABLE I<smiles>c1ccc(CC2=NCCN2)cc1</smiles>

2-benzyliminazoline (BI)<smiles>CN1CCN1Cc1ccccc1</smiles>

$\mathrm{N}$-methyl-2-benzyliminazoline (MeBI)<smiles>CN1CCN=C1Cc1cccc2ccccc12</smiles>

N-methyl-2-(1'-naphthylmethyl)iminazoline (MeNI)<smiles>CN1CCN=C1CN(Cc1ccccc1)c1ccccc1</smiles>

$\mathrm{N}$-methyl-2-(N-benzylanilinomethyl)iminazoline (MeBAI)<smiles>COc1ccc(CC2=NCCN(C)N2C)cc1</smiles>

N-methyl-2-(p-methoxybenzyl)iminazeline (MeMeOBI) hand, $\mathrm{N}$-methylbenzyliminazoline had the same qualitative action as BI itself on cardiac tissue, the intestine, skeletal muscle, and the superior cervical ganglion.

Because of the sudden appearance of a nicotinelike vascular activity of the BI molecule when it contained an $\mathrm{N}$-methyl group, it was decided to compare several more 2-substituted iminazolines with their N-methyl derivatives. The structural formulae of the compounds investigated, and the abbreviations which will be used in referring to them, are given in Table $I$.

The vascular activity of 2-(1'-naphthylmethyl)iminazoline (NI) has been studied by several workers (Hartmann and Isler, 1939 ; Meier and Muller, 1941 ; Emerson, 1944; Craver et al. 1944 ; Yonkman et al., 1945 ; Meier and Bucher, 1946a). 2 - (N - Benzylanilinomethyl)iminazoline (BAI), although studied mainly as an antihistamine compound, was tested for other activities by Meier and Bucher (1946b) and by Craver et al. (1948). p-Methoxybenzyliminazoline (MeOBI) was investigated by Hartmann and Isler in their early paper on the iminazoline series (1939). None of the $\mathrm{N}$-methyl derivatives except MeBI has been mentioned in the literature.

\section{EXPERIMENTAL RESULTS}

\section{A. Action on the cardiovascular system}

(1) Naphthylmethyliminazoline (NI) and MeNI. - The intravenous injection of $25-100 \mu \mathrm{g}$. NI into a spinal cat causes a large rise of blood pressure, but no change in heart rate. The same dose repeated several times causes less rise of blood pressure than the first dose. The pressor effect of NI is not abolished but it may be reduced by large doses of nicotine or tetraethylammonium iodide or by adrenalectomy. Fig. 1 shows the large rise of blood pressure of the spinal cat produced by the injection of $1 \mathrm{mg}$. NI at $\mathrm{C}$ compared to the rise produced by $20 \mu \mathrm{g}$. adrenaline at $\mathrm{A}$ 

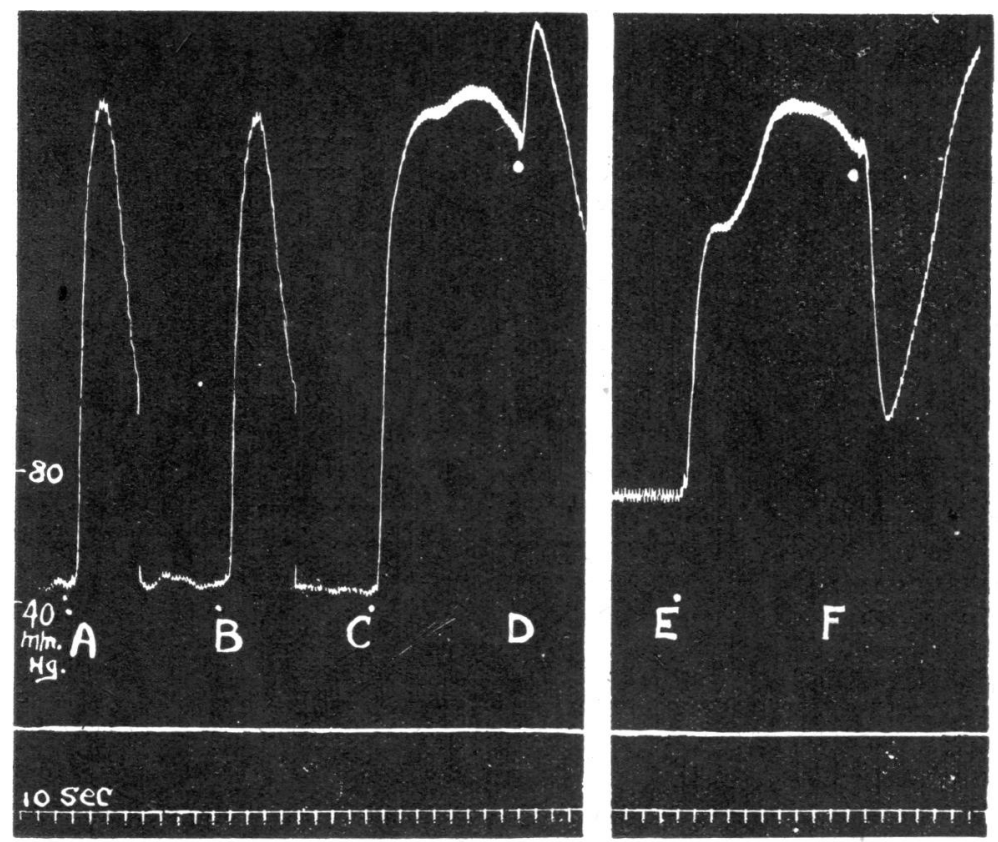

FIG. 1.-Spinal cat. Injections A, B, $20 \mu \mathrm{g}$. adrenaline; C, $1 \mathrm{mg}$. NI; D, $20 \mu \mathrm{g}$. adrenaline; E, $20 \mathrm{mg}$. NI; F, $20 \mu \mathrm{g}$. adrenaline. amplitude. In the isolated perfused rabbit's heart NI caused great depression, but in the dog heart-lung preparation injections up to $10 \mathrm{mg}$. had no appreciable effect on cardiac rate, output, or volume.

NI caused vasoconstriction in the rabbit ear perfused by Locke's solution, and in the dog's hindleg perfused with blood containing heparin by means of a Dale-Schuster pump. The powerful vasocontrictor action of NI is absent in its $\mathrm{N}$-methyl derivative. Thus in the perfused rabbit's ear $2 \mathrm{mg}$. MeNI had no effect, whereas $2 \mu \mathrm{g}$. NI caused a long-lasting vasoconstriction. Thus the unsubstituted compound is and B. It also shows that a large dose $(20 \mathrm{mg}$.) of NI (injected at E) reversed the pressor action of $20 \mu \mathrm{g}$. adrenaline (injected at F). Thus NI, although a pressor substance, reverses the action of adrenaline in large doses. Both ergotoxine and BI abolished the rise of blood pressure caused by NI, but neither reversed it.

Doses of 25-100 $\mu \mathrm{g}$. MeNI have no appreciable effect on the blood pressure, but large doses (1-2 mg.) cause a rapid rise accompanied by an increased heart rate. That this pressor action of MeNI was due to a nicotine-like liberation of adrenaline was shown both in the spinal cat and in the cat under chloralose anaesthesia. Large doses of nicotine abolished this pressor response. It was also found that large doses of MeNI (5-10 mg.) injected during the "nicotine paralysis" caused a fall of blood pressure which was later shown to be due to cardiac depression.

Unlike BI and MeBI, which stimulated the isolated perfused cat's heart, NI and MeNI depressed the heart. Fig. 2 (top) shows the effect of injecting $0.25 \mathrm{mg}$. NI at the $2 \mathrm{nd}$ arrow ; the heart rate decreased by eight beats $/ \mathrm{min}$., the coronary flow from 5.2 to $4.2 \mathrm{ml} . / \mathrm{min}$., and the force of contraction by 40 per cent. At the 1 st arrow $0.25 \mathrm{mg}$. MeNI caused a similar decrease in heart rate and coronary flow, but less reduction in
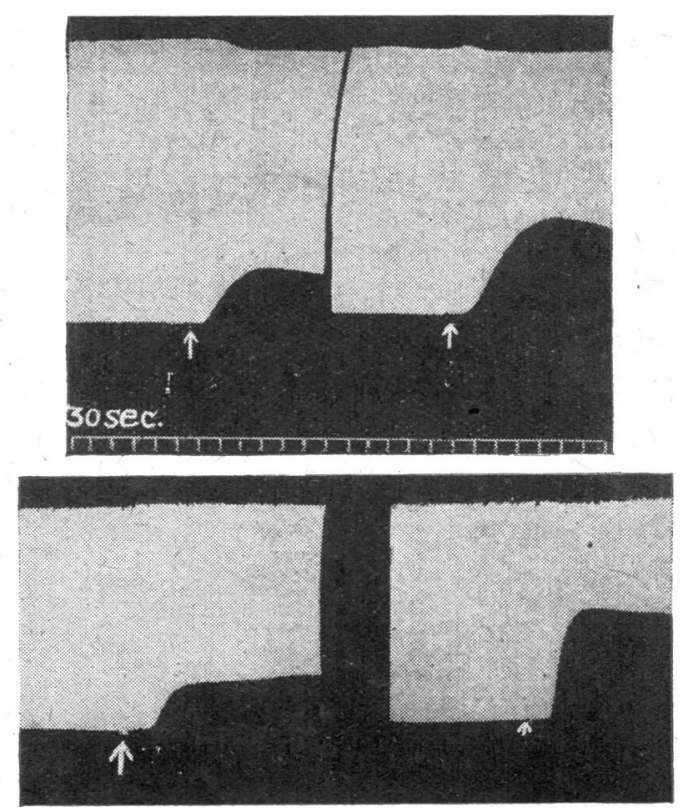

Fio. 2.-Cat heart, Langendorff preparation. Upper record, 1st arrow, 0.25. mg. MeNI; 2nd arrow, $0.25 \mathrm{mg}$. NI. Lower record, $1 \mathrm{st}$ arrow, $0.25 \mathrm{mg}$. MeBAI; 2nd arrow, $0.25 \mathrm{mg}$. BAI. 


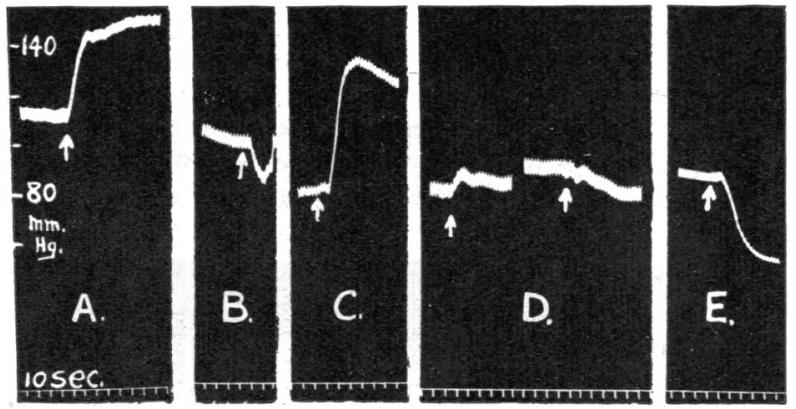

Fig. 3.-Cat, chloralose. A, $5 \mathrm{mg}$. MeMeOBI; B, $10 \mathrm{mg}$. MeOBI; C, $2 \mathrm{mg}$. MeBAI; between C and D, $19 \mathrm{mg}$. nicotine acid tartrate injected; in $D$, first $5 \mathrm{mg}$. MeMeOBI, second 2 mg. MeBAI. E, 2 mg. BAI.

over 1,000 times as active a vasoconstrictor as its $\mathrm{N}$-methyl derivative in this preparation.

(2) Benzylanilinomethyliminazoline $(B A I)$ and $M e B A I$. - Fig. $3 \mathrm{C}$ shows the abrupt rise of the cat's blood pressure produced by injecting $2 \mathrm{mg}$. MeBAI ; the same dose of the unsubstituted compound injected at $\mathrm{E}$ caused a long-lasting depressor response. After large doses of nicotine the pressor response to $2 \mathrm{mg}$. MeBAI (injected at 2nd arrow in D) was abolished. Thus it was concluded that the rise of blood pressure caused by MeBAI was also a nicotine-like effect.

Both BAI and MeBAI depressed the isolated perfused cat's heart. The effect of injecting 0.25 mg. of those compounds is shown in Fig. 2 (bottom). The reduction in heart rate and force of contraction was similar to that caused by the naphthyl compounds, but the coronary flow was first increased by the benzylanilino compounds before the longer-lasting reduction occurred.

In the isolated perfused rabbit's ear it was found that the injection of $1 \mathrm{mg}$. BAI or MeBAI produced definite vasodilatation. The N-methyl compound seemed somewhat weaker in this respect than the parent substance.

(3) p-Methoxybenzyliminazoline (MeOBI) and $M e M e O B I$. - These compounds will be seen (Fig. 3) to have the same general action on the cat's blood pressure as BAI and MeBAI. Thus $5 \mathrm{mg}$. MeMeOBI injected at $A$ caused a rise of blood pressure and increased the heart rate; this pressor response was no longer significant when the same dose was injected, at the first arrow in $D$, after nicotine; $10 \mathrm{mg}$. MeOBI caused a fall of blood pressure when injected at $B$. The depressor action of MeOBI is not the same as that of BAI, however, because it was found that $10-20 \mathrm{mg}$. MeOBI injected into a spinal cat reversed the pressor effect of small doses of adrenaline in the same way as BI had done. Further experiments showed that very large doses of adrenaline caused a pressor effect after MeOBI as they had been shown to do after BI.

The isolated perfused cat heart was depressed by both MeOBI and its $\mathrm{N}$-methyl derivative. In this respect the methoxybenzyl compounds were unlike BI and MeBI.

B. Action on the intestine.-The normal tone of the isolated guinea-pig ileum was reduced by NI, BAI, and MeBAI, by $\mathrm{MeOBI}$, and MeMeOBI. These compounds also antagonized the contractions induced by acetylcholine. NI in a concentration of $4 \times 10^{-6}$ was shown to reduce greatly the histamine-induced ileal contraction (see Fig. 4A). On the other hand, MeNI $\left(5 \times 10^{-7}\right)$ produced a slowly developing contraction of the ileum which was slightly less than that caused by acetylcholine $\left(2 \times 10^{-9}\right)$. If an insufficient interval was left between doses of MeNI, the stimulating
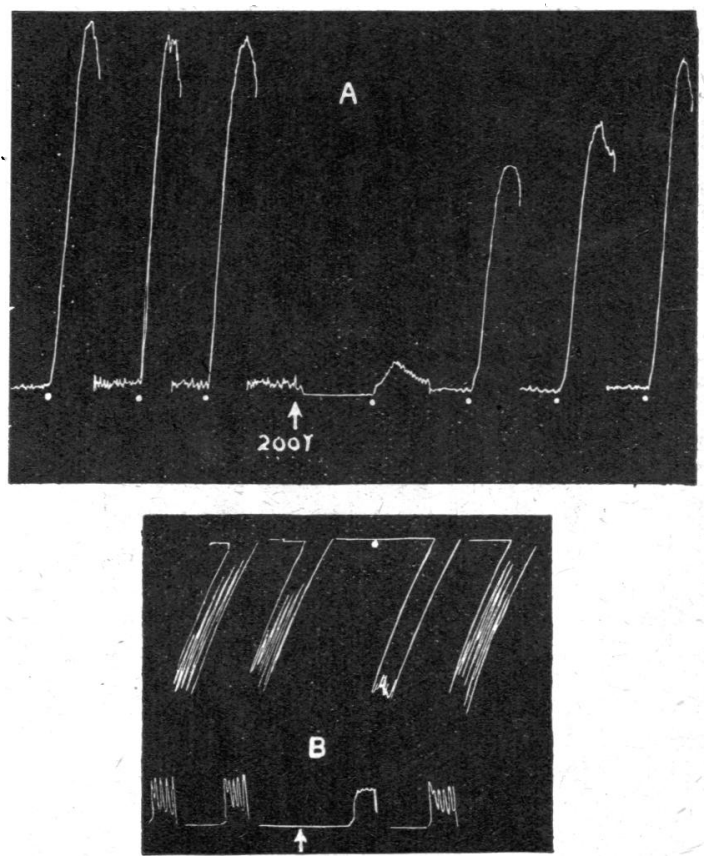

Fig. 4.-Guinea-pig ileum, $50 \mathrm{ml}$. bath Locke's solution. A: $0.2 \mu \mathrm{g}$. histamine at each dot; $0.2 \mathrm{mg}$. NI at the arrow. B : Trendelenburg preparation, upper record showing peristalsis, lower record longitudinal contractions. At arrow MeMeOBI was added to bath so that the concentration was $4 \times 10^{-5}$, addition being made 2 min. before the next stimulus. 
effect was reduced or lost completely, presumably because nicotine-like paralysis occurred.

The pendulum movements of the isolated rabbit's duodenum were inhibited by NI in a concentration of $10^{-7}$, about ten times the dose of adrenaline required to produce the same effect. MeNI in a concentration of $2 \times 10^{-6}$ increased the tone and rhythm of the intestine, and prevented the inhibitions regularly caused by $4 \times 10^{-6} \mathrm{NI}$.

In the Trendelenburg peristalsis preparation as modified by Feldberg and Lin (1948) NI was found to have no effect on the peristalsis, but it inhibited the longitudinal contractions of the ileum. BAI, MeOBI, and its $\mathrm{N}$-methyl derivative inhibited both sets of muscle fibres. The inhibitory effect of $4 \times 10^{-5} \mathrm{MeMeOBI}$ on the circular and longitudinal muscles of the ileum is shown in Fig. 4B.

C. Action on skeletal muscle.-All tnese iminazolines, substituted or not, caused a curariform block in the transmission of the nerve impulse in the phrenic nerve-diaphragm preparation of the rat.
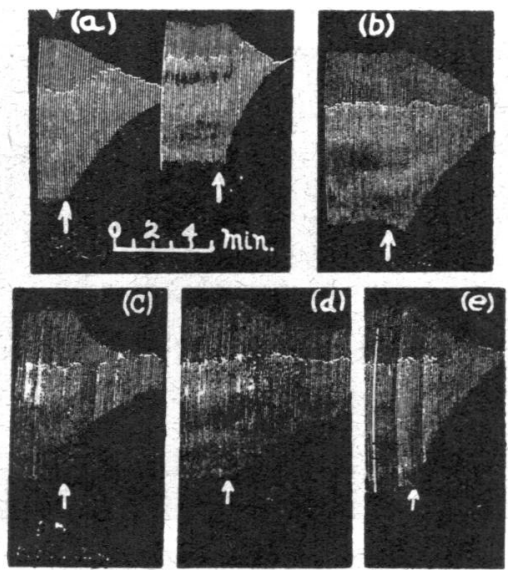

Fig. 5.-Rat phrenic nerve-diaphragm preparation. Stimulation with maximal shocks 6-12/min. Bath $50 \mathrm{ml}$. $\mathrm{T}=36^{\circ} \mathrm{C}$. (a) 1st arrow, $10 \mathrm{mg}$. NI; 2nd arrow, $10 \mathrm{mg}$. MeNI. (b) $10 \mathrm{mg}$. BAI. (c) 10 mg. MeMeOBI. (d) 10 mg. MeOBI. (e) MeBAI. All substances allowed to act for $5 \mathrm{~min}$.

Fig. 5 illustrates this action; all the compounds were given in a final concentration of $2 \times 10^{-4}$. Although slight differences in potency were observed, the curarizing effects of these compounds were all of the same order of magnitude.

Curariform activity was also observed in the sciatic-gastrocnemius preparation of the cat. Fig. 6 shows the decreased muscle tension produced by the intra-arterial injection of the various $\mathrm{N}$-methyl derivatives. The parent compounds have the same curarizing action and with doses of the same order of magnitude. That this was a true curariform action and not a direct effect on the nerve or on the muscle was shown by the following experiments. The intra-arterial injection of a large dose
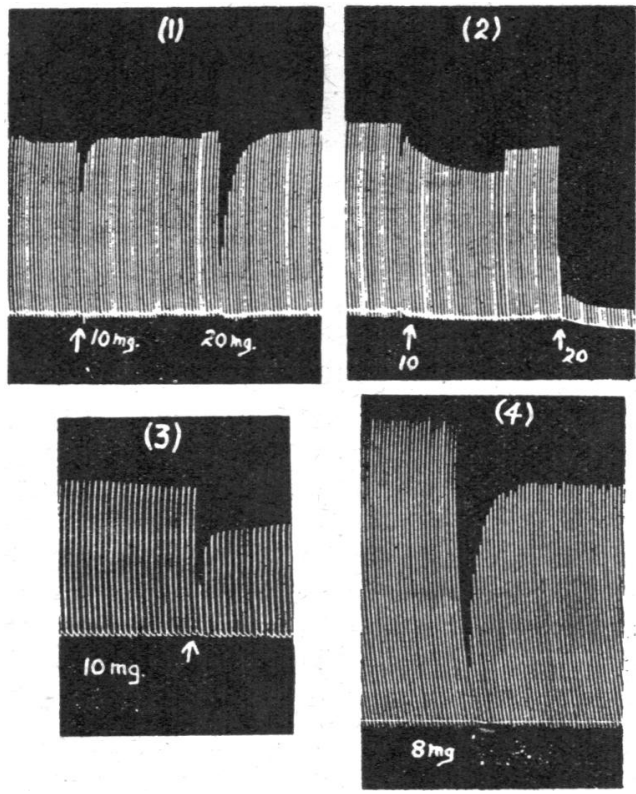

Fig. 6.-Cat, chloralose, left sciatic-gastrocnemius preparation; record of gastrocnemius contraction with tension lever. Injections made into aorta at the biturcation through the stump of the right external iliac artery. (1) $10 \mathrm{mg}$. and $20 \mathrm{mg}$. MeMeOBI; (2) $10 \mathrm{mg}$. and $20 \mathrm{mg}$. MeBAI; (3) $10 \mathrm{mg}$. MeNI; (4) $8 \mathrm{mg}$. MeBI.

(20 mg.) of MeNI into the fully curarized, directly stimulated gastrocnemius of the cat did not alter the tension developed in the muscle. Nor did MeNI in a concentration of $10 \mathrm{mg} . / \mathrm{ml}$. applied directly to the nerve of the isolated frog's nervemuscle preparation cause any change in the twitch tension evoked by stimulation through the nerve.

D. Action on the perfused superior cervical ganglion.-Since the N-methyl compounds of this series shared the nicotine-like pressor action of MeBI, it was expected that they might, like MeBI and nicotine, stimulate the ganglion before depressing its response to preganglionic stimulation. But although depression or abolition of ganglionic transmission occurred with all the compounds, $\mathrm{N}$ methyl-substituted or not, none of them caused a stimulation of the ganglion cells on injection as MeBI had done. A typical example of the curari- 
on the isolated heart and perfused vessels, on the intestine, and on ganglionic and neuromuscular transmission have been compared with those of their N-methyl derivatives.

$\mathrm{N}$-methylation was found to cause a shift in the site of action so that the effect of these compounds on the blood pressure was not due to a direct action on the peripheral vascular system but was the resultant of more central actions: stimulation of sympathetic ganglia, liberation of adrenaline, and direct effect on the cardiac muscle.

Nicotine-like activity on the isolated intestine was shown only by $\mathrm{N}$-methyl-(naphthylmethyl)iminazoline; the other compounds inhibited the tone, and antagonized the contractions evoked by acetylcholine. (N-Benzylanilinomethyl)iminazoline, $p$-methoxybenzyliminazoline, and their $\mathrm{N}$-methyl derivatives had a curariform effect on intestinal peristalsis.

All the compounds of this series, whether Nmethylated or not, showed curariform activity on the superior cervical ganglion and on neuromuscular transmission.
I am indebted to Dr. W. F. Short and Dr. P. Oxley, of Boots Pure Drug Co., for the compounds used in this study; I also wish to thank Professor J. H. Burn and Dr. G. S. Dawes for their guidance and encouragement.

\section{REFERENCES}

Barlow, R. B., and Ing, H. R. (1948). Brit. J. Pharmacol., 3, 298.

Craver, B. N., Chase, H. F., and Yonkman, F. F. (1944). J. Pharmacol., 82, 275.

Craver, B. N., Barrett, W., Cameron, A., Hays, H., Holmquist, G., Mackenzie, A., and Smith, J. (1948). Fcd. Proc., 7, 213.

Emerson, G. A. (1944). J. Phämacol., 82, 42.

Feldberg, W., and Lin, C. Y. (1948). J. Physiol., 107, 37 P.

Feldberg, W., and Vartiainen, A. (1934). J. Physiol., 83, 103.

Gowdey, C. (1948). Brit. J. Pharmacol., 3, 254.

Hartmann, M., and Isler, H. (1939). Arch. exp. Path. Pharmak., 192, 141.

Meier, R., and Bucher, K. (1946a). Helv. physiol. Acta, 4, 69.

Meier, R., and Bucher, K. (1946b). Schreiz. med. Wschr., 76. 294.

Meier, R., and Muller, R. (1941). Schweiz. med. Wschr., 71, 554.

Yonkman, F. F., Rennick, B., and Schwerma, H. L. (1945). J. Pharmacol., 84, 197. 